\title{
Business Process Service Oriented Methodology (BPSOM) with Service Generation in SoaML
}

\author{
Andrea Delgado ${ }^{1}$, Francisco Ruiz ${ }^{2}$, Ignacio García-Rodríguez de Guzmán ${ }^{2}$, \\ and Mario Piattini ${ }^{2}$ \\ ${ }^{1}$ Computer Science Institute, Faculty of Engineering, University of the Republica \\ Julio Herrera y Reissig 565 \\ CP 11300, Montevideo, Uruguay \\ ${ }^{2}$ Alarcos Research Group, Information Tech \& Systems Dep., University of \\ Castilla-La Mancha \\ Paseo de la Universidad No.4 \\ CP 13071, Ciudad Real, España \\ adelgado@fing.edu.uy, \\ \{francisco.ruizg, ignacio.grodriguez, mario.piattini\}@uclm.es
}

\begin{abstract}
Carrying out business processes by means of software services helps to close the business-systems gap, by introducing an intermediate layer between business process definition and software systems, thus permitting not only better independence, but also more traceability between them. Despite the fact that technologies have matured to support this new reality, there is a lack of methodologies and notations, although some have been proposed to guide service development with different visions of service design and implementation. Service modeling is the basis for, among other things, the automation of several development steps by means of the model-driven development paradigm. The SoaML standard is a major step towards service modeling in UML. In this paper we extend our Business Process Service Oriented Methodology (BPSOM) for service development from business processes by integrating two main aspects: service modeling using SoaML and QVT transformations to obtain SoaML service models from BPMN BP models.
\end{abstract}

Keywords: Business Process Management (BPSOM), Service Oriented Computing (SOC), Model Driven Development (MDD), BPMN, SoaML.

\section{Introduction}

The modeling of business process as the means to show explicitly how organizations carry out their business has gained importance in recent years. Although the business area has several mature techniques with which to manage its business processes, based on the Business Process Management (BPM) [1][2] paradigm, the software area has recently been integrating this vision into software development, supported by the Service Oriented Computing (SOC) [3] paradigm. Carrying out business processes by means of software services based on a Service Oriented Architecture (SOA) [4][5] style, helps to close the business-system gap which has come about as a result of the differences between business and software area visions of the organization. The 
Model Driven Development (MDD) [6] paradigm, along with Model Driven Architecture (MDA) [7] have an important role to play. They allow correspondences between models to be defined, since they are key development artifacts, permitting the generation of code in different technologies. Although technologies have matured to support this new reality, few methodologies have been proposed to guide the service development process. The Service Oriented Architecture Modeling Language (SoaML) [8], recently defined by OMG, is a major step towards the modeling of services using UML and specific service stereotypes.

The standardized framework MINERVA [9] we have defined aims to support the Business Process (BP) lifecycle [1] by applying service-oriented and model-driven paradigms to business processes; it can be viewed on-line in [10]. The Business Process Service Oriented Methodology (BPSOM) [11] integrated in MINERVA provides the methodological guide with which to develop services from business processes. This paper extends the definition of BPSOM shown in [11] by integrating two new key aspects: the use of the SoaML standard for service modeling, and transformations using the Query/Views/ Transformations (QVT) [12] language, to generate SoaML service models, when possible, from business process models in Business Process Modeling Notation (BPMN) [13].

The remainder of the paper is organized as follows: BPSOM is presented in Section 2, along with the use of BPMN for BP modeling and SoaML for service modeling. In Section 3 service generation from business process is presented, related work is described in Section 4, and conclusions and future work are in Section 5.

\section{BPSOM Definition}

BPSOM has been defined for integration into the existing software development process used in the organization, with the aim of reusing existing knowledge, by adding only specific elements for service oriented development from business processes. Fig. 1 shows the definition of BPSOM and its use within the base process.

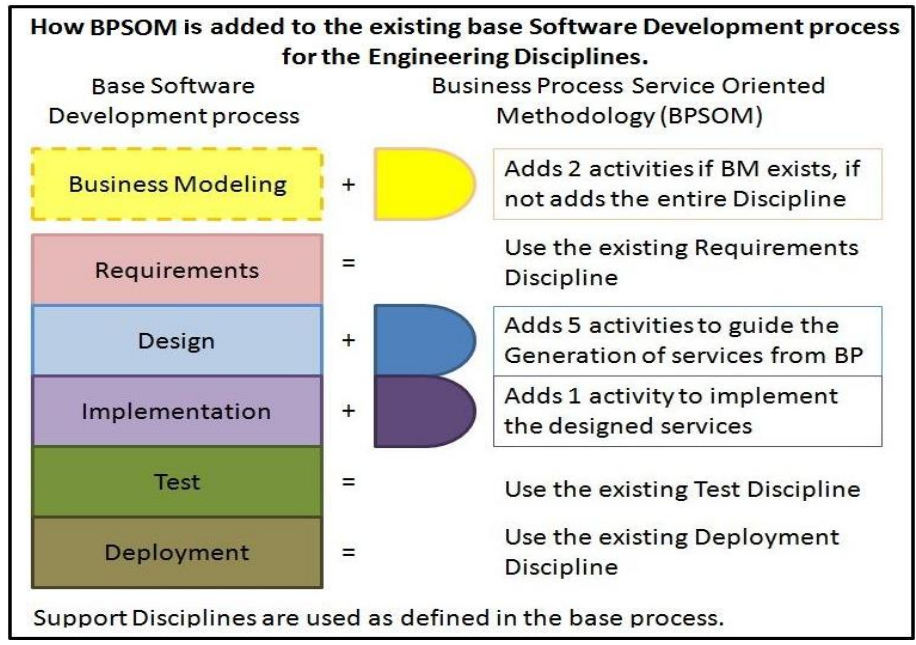

Fig. 1. How BPSOM is added to the existing software development process 
We have based our work on the broad idea of methodology as outlined in [14]: a set of methods or techniques related, along with a process model and a set of deliverables, metrics, tools and management guidelines (including roles and organization team work). The definition of BPSOM began in 2005 and its disciplines, activities, roles and artifacts are detailed in [11]. In this paper we focus on the extension of BPSOM by adding service modeling in SoaML, along with the automatic generation of SoaML service models from BPMN BP models through QVT transformations, first described in [15]. The key aspect is to show where and how to use SoaML diagrams in BPSOM, as the standard provides their description, but no guide for using them. Transformations help obtaining some of the SoaML models automatically, providing support to activities, although human intervention is needed.

\subsection{BPMN Use in the BPSOM Business Modeling Discipline}

There is a great variety of notations for business process modeling [16], although in recent years, BPMN has emerged as the one preferred. Business people can use it to model business processes by themselves and then pass it to the software area.

BM1 - Assess the target organization. This activity aims to involve the project team in the organization for which the development is being carried out. The participating roles in this activity are the Business Analyst (from the business area), the Analyst and the Architect (from the software project team). The OMG Business Motivation Model (BMM) [17] can also be used for modeling goals and information which can be linked to SoaML services.

BM2 - Identify Business Processes. This is one of the key activities in the development of services from BP, since it is the main input needed to understand and describe $\mathrm{BP}$ in the organization. We use BPMN to specify them, which provides elements such as swimlanes (pool, lane), flow objects (activities, gateways), connecting objects (sequence, message) and artifacts (group, data) to model BP. Fig. 2 shows the "Patient Admission and Registration for Major Ambulatory Surgery (MAS)" BP from the Ciudad Real General Hospital project on which we are working, adapted to be used as example.

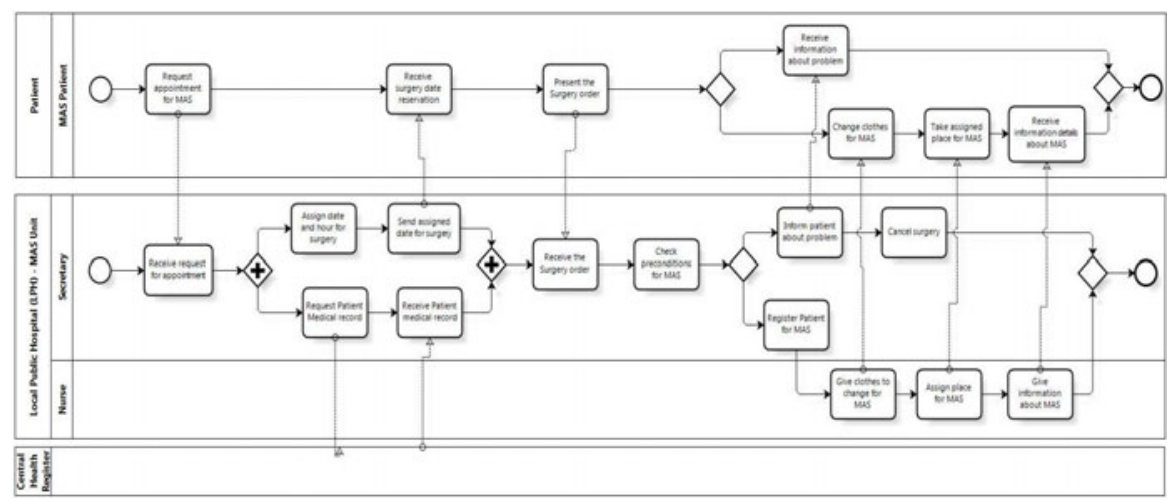

Fig. 2. "Patient Admission and Registration for MAS" Business Process in BPMN 


\subsection{SoaML Use in BPSOM Design Discipline}

There is also a wide choice of notations for service modeling [16], UML being the one preferred. The SoaML profile extends UML by adding specific elements for service modeling, and will therefore soon be adopted by the community. It provides several stereotypes with which to specify services (contract, interfaces, operations, parameters) and the service architecture for the business process.

D1 - Identify and categorize services. This activity aims to identify the services needed to perform the business process under development and it is a key one in our approach. One of the main inputs of this activity is the BP model specified previously. The use of SoaML implies defining the Service Architecture (SA) which specifies the participants, contracts for the services and the roles they play as provider or consumer. Fig. 3 shows the SoaML SA for the example.

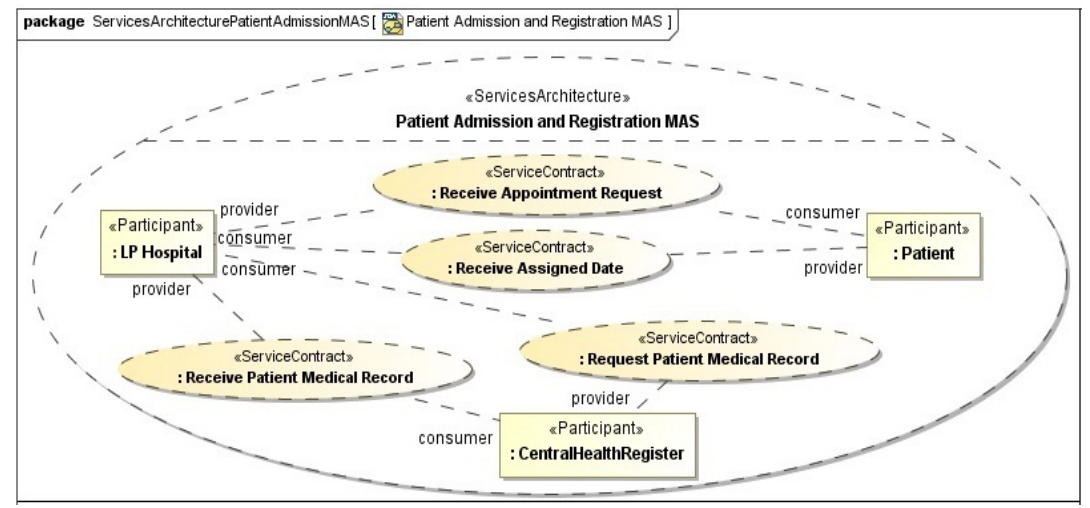

Fig. 3. SoaML ServicesArchitecture diagram for business process in Fig. 2

Services that the organization needs to provide to other parties and services that the organization has to consume from other parties are identified, based on the messages exchanged, each party being defined by a pool. To identify the services to support the business process, we look at each message exchanged between the pools (participants), setting the activity type to "ServiceTask" when we define it as a service. The ones that present incoming messages will be providers and those with outgoing

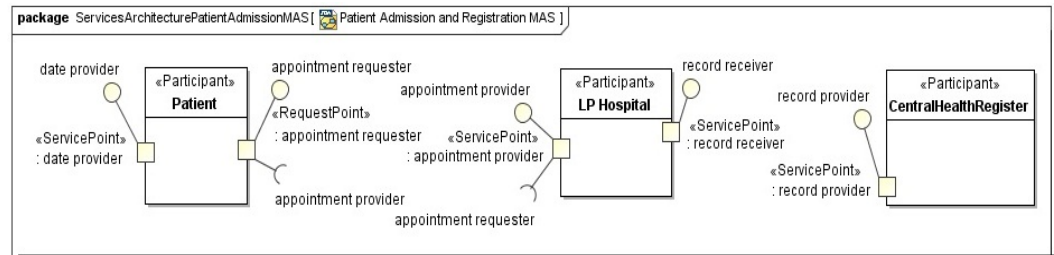

Fig. 4. Service and Request Ports for Participants 
messages to a service task will be consumers. Services will be assigned to the participant corresponding to the pool containing each activity, and the associated Service Contract will hold all service information. Fig. 4 displays some Service and Request Ports (formerly Points) for the services defined, showing the bidirectional and unidirectional pattern of communication that can be defined.

D2 - Specify services. The specification of services corresponds to the definition of all the information needed, including the associated Service Contract with interfaces, operations, input and output parameters, among others. The information related to the in and out messages must be specified, indicating the parameters and data to be exchanged between the parties. The choreography defined by the Service Contract must also be specified, based on the interaction between participants. Once all this information has been considered, the most important parts of the ServiceContract can be generated and this can then be completed by the Architect or developers, who will also have to give the implementation details. Fig. 5 presents the ServiceContract definition and its choreography for the "ReceiveAppointmentRequest" service.

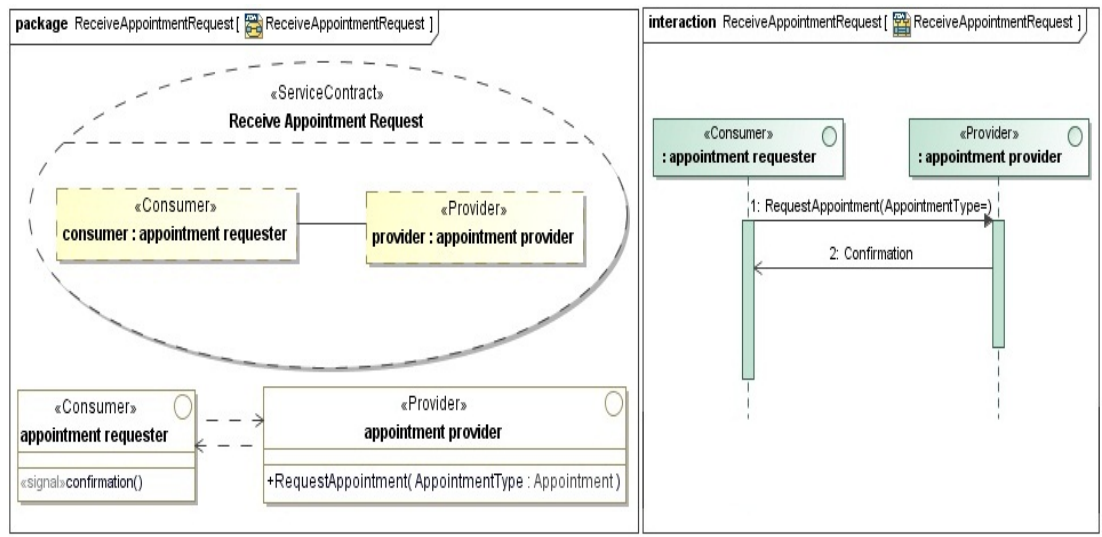

Fig. 5. ServiceContract and Choreography for the "ReceiveAppointmentRequest" service

D3 - Investigate existing services. The principal goal of this activity is to reuse the organization's existing services, as far as possible. To do so, a central Service Catalogue is defined, which has to be searched in each service development project. In the SoaML component diagram an adapter or wrapper has to be defined to relate the design service to its existing implementation, linking them in activity D4.

D4 - Assign components to services. The components that will implement the services generated must be defined and shown in the components diagram. For each service, a component with which to implement it has to be defined. SoaML provides the participant component with which to define the implementation of participants and services, defining new components to be generated and, if one exists, defining adapters or wrappers to use it. 
D5 - Define services interaction. Service interaction can be defined as the orchestration or choreography of services, [4][5], as is done for business processes. This insight is provided by a sequence diagram showing all the services, or by various diagrams showing subsets of services for different sub-processes in the BP. That activity has no corresponding diagram in SoaML, so it is shown by a UML sequence diagram.

\section{From BPMN Models to SoaML Models and Beyond}

The BPSOM methodological and automated guide is used to derive and generate services from BP models, thus constituting the basis for its implementation. BPSOM defines how to derive services from BP in a conceptual manner. It identifies the participants involved and the services they provide and request, along with the associated contracts and interfaces, parameters, and the messages exchanged, using the SoaML standard. The automation in BPSOM focuses on the generation of services from BP by means of QVT transformations defined between the SoaML and the BPMN metamodels. We follow the MDA approach based completely on the use of OMG standards. The BPMN BP model constitutes the CIM, and the SoaML service model the PIM, which can then be used to generate code, using MDA engines. The QVT transformations are based on a defined ontology [18] which relates BP models to service models, conceptualizing their elements and relationships. Fig. 6 shows an overview of the relationship between the BP in Fig. 2 and ServicesArchitecture in Fig. 3. The QVT transformations code itself is not shown here, as it can be seen in [15].

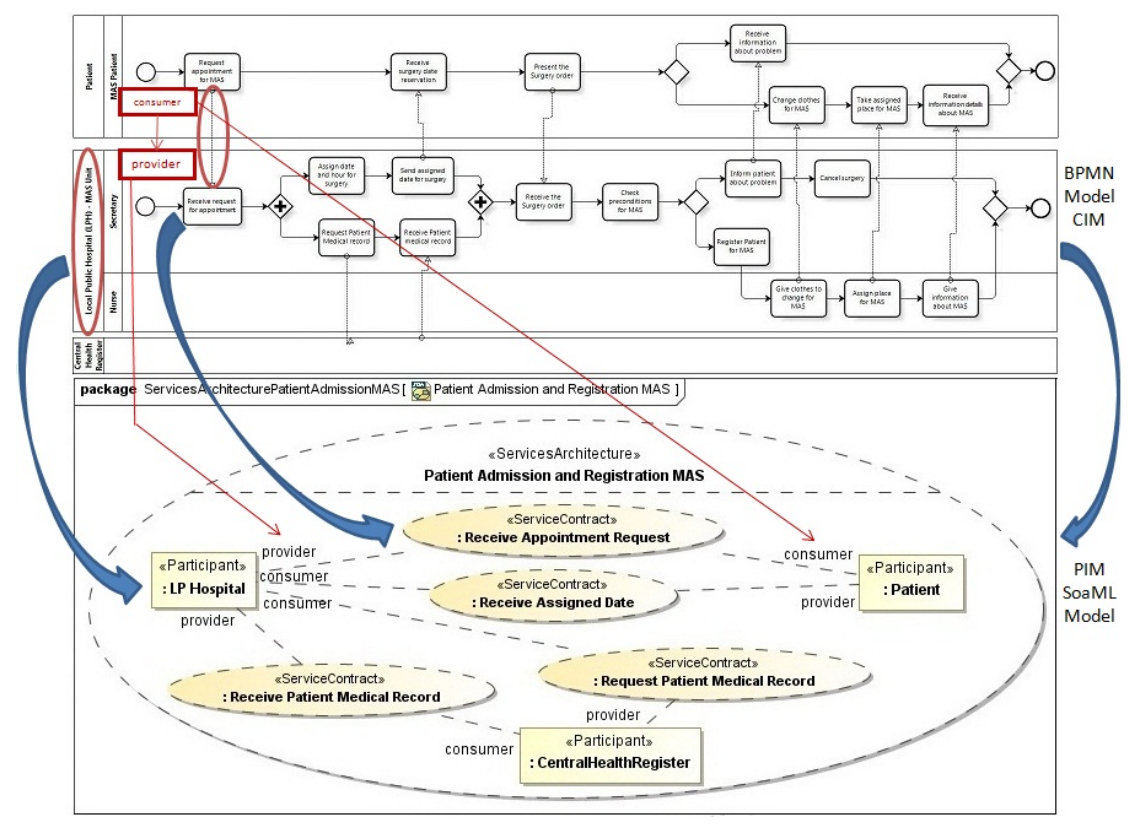

Fig. 6. BPMN to SoaML QVT transformations definitions for the example 
We use the Eclipse environment in MINERVA, integrating several plug-ins to support BPSOM definitions, including MediniQVT as the QVT engine. The BPMN BP model is created by business and software people in a BPMN modeler which exports the model. It is then loaded into Eclipse and marked by the Architect with information to apply the QVT transformations, obtaining participants and its ports. To generate the code, the MDA engine needs all the SoaML diagrams, completed later by developers. For the example, we have integrated the MagicDraw Cameo SOA+ and ModelPro Eclipse plug-ins, which can be downloaded from [19] with the BPMN BP and SoaML services models, QVT transformations and input and output XMI files.

\section{Related Work}

We carried out a systematic review regarding the application of SOC and MDD paradigms to BP, presented in [16]. To the best of our knowledge, there is no other work that relates BPMN models directly to SoaML models the way we do. Regarding the methodological approach, BPSOM has been defined over the same period as other proposals shown in [11][16]. Nevertheless, it is worth mentioning [20], which defines a methodology for service development focusing on WS, the survey of methodologies presented in [21], as well as a consolidated methodology for defining business and software services, the SOMA plug-in for the RUP [22], which, as ours does, adds activities, but to RUP, and Shape [23] ,which also uses SoaML, but with different guides and no generation. For the model driven approach it is worth mentioning [24], which defines guidelines and transformations from one model to other, [25] proposing a method for service composition with a process to model generation, metamodels and artifacts to be obtained, adding in [26] a value model for deriving services using ATL [27].This is also used in [28], in which models, metamodels and transformations are defined, moving from collaborative BP to a SOA model, generating BPEL. Our proposal differs from these in several ways: firstly, BPSOM can be added to any existing base software development process, thus promoting reuse and making it easier to adopt. Secondly, QVT transformations are integrated in the development environment, obtaining the models from which to generate code. Thirdly, the conceptual and automatic guide is fully integrated in BPSOM. Finally, MINERVA framework integrates existing standards, promoting standardization of development.

\section{Conclusions and Future Work}

BPSOM has been defined to guide service development from business processes, integrated into MINERVA framework for continuous BP improvement. Its contributions are as follows: it allows the reuse of existing knowledge in the developing organization, by using the base software development process, adding specific elements for service development. The use of the SoaML standard to model services supports the definition of meaningful elements in specifying services from BP, in both a conceptual and an automatic way. Finally, we have defined QVT transformations from the BPMN metamodel to the SoaML metamodel that can be executed in the Eclipse environment, obtaining an initial definition of service models. These QVT transformations were defined for previous versions of BPMN and SoaML, so we are updating 
and completing them using the BPMN 2.0 and SoaML beta2 standards recently released by OMG. There are few implementations of SoaML, so we are developing our own to show the service models graphically. From these diagrams, code can be generated using existing MDA engines. We are working on case studies at the Ciudad Real General Hospital to validate the proposal.

Acknowledgments. This work has been partially funded by the Agencia Nacional de Investigación e Innovación (ANII,Uruguay), ALTAMIRA project (Junta de Comunidades de Castilla-La Mancha, Spain, F. Soc. Europeo, PII2I09-0106-2463), PEGASO/MAGO project (Ministerio Ciencia e Innovacion MICINN, Spain, FEDER, TIN2009-13718-C02-01) and INGENIOSO project (Junta de Comunidades de CastillaLa Mancha, Spain, PEII11-0025-9533).

\section{References}

1. Weske, M.: BPM Concepts, Languages, Architectures. Springer, Heidelberg (2007)

2. Smith, H., Fingar, P.: Business Process Management:The third wave. Meghan-Kieffer, Tampa (2003)

3. Papazoglou, M., Traverso, P., Dustdar, S., Leymann, F.: Service-Oriented Computing: State of the Art and Research Challenge. IEEE Computer Society, Los Alamitos (2003)

4. Krafzig, D., Banke, K., Slama, D.: Enterprise, SOA, Best Practices. Prentice-Hall, Englewood Cliffs (2005)

5. Erl, T.: SOA: Concepts, Technology, and Design. Prentice-Hall, Englewood Cliffs (2005)

6. Mellor, S., Clark, A., Futagami, T.: Model Driven Development. IEEE Comp.Society, Los Alamitos (2003)

7. Object Management Group (OMG), Model Driven Architecture, MDA (2003)

8. Object Management Group (OMG), SOA Modeling Language, SoaML (2009)

9. Delgado, A., Ruiz, F., García-Rodríguez de Guzmán, I., Piattini, M.: MINERVA: Model drIveN and sErvice oRiented framework for the continuous business process improVement and relAted tools. In: Dan, A., Gittler, F., Toumani, F. (eds.) ICSOC/ServiceWave 2009. LNCS, vol. 6275, pp. 456-466. Springer, Heidelberg (2010)

10. Delgado, A.: MINERVA framework (2010), http://alarcos.esi.uclm.es/MINERVA/

11. Delgado, A., Ruiz, F., García - Rodríguez de Guzmán, I., and Piattini, M.: Towards a Service-Oriented and Model-Driven framework with business processes as first-class citizens. In: 2nd International Conference on BP and Services Computing, BPSC 2009 (2009)

12. Object Management Group (OMG), Query/Views/Transformations, QVT (2008)

13. Object Management Group (OMG), Business Process Modeling Notation, BPMN (2009)

14. Graham, I., Henderson-Sellers, B., Younessi, H.: The OPEN Process Specification. ACM Press, Addison-Wesley(1997)

15. Delgado, A., García - Rodríguez de Guzmán, I., Ruiz, F., Piattini, M.: From BPMN business process models to SoaML service models: a transformation-driven approach. In: 2nd Int.Conf. on Software Tech. and Engineering (ICSTE 2010), San Juan de Puerto Rico (October 2010)

16. Delgado, A., Ruiz, F., García-Rodríguez de Guzmán, I., Piattini, M.: Application of service-oriented computing and model-driven development paradigms to BP: a systematic review. In: 5th Int. Conf. on SW and Data Technologies (ICSOFT 2010), Athens (2010)

17. Object Management Group (OMG), Business Motivation Model, BMM (2010)

18. Delgado, A., Ruiz, F., García-Rodríguez de Guzmán, I., Piattini, M.: Towards an ontology for SO modeling supporting BP. In: 4th. Int. Conf. on Research Challenges IS, RCIS 2010 (2010) 
19. Delgado, A.: BPSOM methodology example (2010), http://alarcos.esi.uclm.es/MINERVA/BPSOM/BPSOMexample.zip

20. Papazoglou, M., van den Heuvel, W.: Service-oriented design and development methodology. Int. J. Web Engineering and Technology 2(4), 412-462 (2006)

21. Kohlborn, T., Korthaus, A., Chan, T., Rosemann, M.: Identification and Analysis of Business and SE Services- A Consolidated Approach. IEEE Transactions on Services Comp. (2009)

22. IBM-SOMA, http://www.ibm.com/developerworks/rational/ downloads/06/rmc_soma/

23. Stollberg, M., et al.: A Customizable Methodology for the MDE of Service-based System Landscapes. In: 4th Workshop on Modeling, Design, and Analysis for the Service Cloud (MDA4ServiceCloud 2010), with ECMFA 2010, Paris (June 2010)

24. Herold, S., Rausch, A., Bosl, A., Ebell, J., Linsmeier, C., Peters, D.: A Seamless Modeling Approach for service-oriented IS. In: 5th Int. Conf. on IT:New Generations, ITNG 2008 (2008)

25. de Castro, V., Marcos, E., López Sanz, M.: A model driven method for service composition modelling: a case study. Int. J. Web Engineering and Technology 2(4) (2006)

26. de Castro, V., Vara Mesa, J.M., Herrmann, E., Marcos, E.: A Model Driven Approach for the Alignment of Business and Information Systems Models (2008)

27. Jouault, F., Kurtev, I.: Transforming models with ATL (ATLAS Transformation Language). In: Bruel, J.-M. (ed.) MoDELS 2005. LNCS, vol. 3844, pp. 128-138. Springer, Heidelberg (2006)

28. Touzi, J., Benaben, F., Pingaud, H., Lorré, J.P.: A model-driven approach for collaborative service-oriented architecture design. Int. Journal of Prod. Economics 121(1) (2009) 